\title{
El reconocimiento de nuevas formas de familia en Colombia: retos pastorales y morales a la misión evangelizadora de la iglesia a la luz del sínodo y de "Amoris Laetitia"
}

\author{
Ricardo Azael Escobar Delgado**
}

Recibido: 13 de septiembre de 2016 • Aprobado: 06 de octubre de 2016.

\section{Resumen:}

El artículo que ponemos a la consideración del lector es el resultado de una investigación sobre la familia: su naturaleza, su realidad, su clasificación y tipología; así como el desarrollo de la jurisprudencia de la Corte Constitucional de Colombia, que ha dado lugar a un proceso de evolución en el concepto de la familia y las nuevas formas de familia, reconocidos en el ordenamiento jurídico del país. También se ocupa de la posición de la iglesia contra el concepto de la familia y de las nuevas formas de familia. Los retos legales, éticos, culturales, morales para el país y para la Iglesia en su obra de evangelización y humanización, desde el Sínodo de la familia 2014 - 2015 y sobre todo de la Exhortación Apostólica "Amoris Laetitia" del Papa Francisco.

Palabras clave: Familia, Corte Constitucional, legislación, moral, Amoris Laetitiae.

* El presente artículo es informe de avance de investigación de la tesis doctoral: "Evangelización de las nuevas formas de familia en Colombia a la luz del Sínodo de la familia y de la exhortación Apostólica Postsinodal Amoris Laetitia". Escuela de teología, filosofía y humanidades. Universidad Pontificia Bolivariana. Medellín 2016.

* PhD. Doctor en ciencias políticas y sociología, Universidad Pontificia de salamanca, Madrid - España. Candidato a Doctor en Teología, Universidad Pontificia Bolivariana, Medellín - Colombia. Especialista en gerencia de Instituciones de Educación Superior; especialista en Docencia Universitaria: especialista en Derechos Humanos. Universidad Santo Tomás - Bogotá. Licenciado en Filosofía, y Licenciado en Filosofía y Ciencia Religiosas, Universidad Santo Tomás, Bogotá. Docente investigador del centro de humanismo cristiano de la escuela de teología, filosofía y humanidades. Integrante del Grupo de investigación GIEB. Universidad Pontificia Bolivariana. Medellín - Colombia. Email: ricardoazael.escobar@upb.edu.co. 


\title{
The recognition of new forms of family in Colombia: pastoral and moral challenges to the evangelizing mission of the church in the light of the synod and of "Amoris Laetitia"
}

\begin{abstract}
:
The article we present for the reader's consideration is the result of a research about the family: its nature, its reality, its classification and typology; as well as the development of the jurisprudence of the Colombian Constitutional Court, which has given rise to a process of evolution in the concept of family and new forms of family recognized in the country's legal system. It also deals with the position of the church against the concept of family and new forms of family. The legal, ethical, cultural and moral challenges for the country and for the Church in its work of evangelization and humanization, since the Synod on the Family 2014-2015 and above all of the Apostolic Exhortation "Amoris Laetitia" by Pope Francis.
\end{abstract}

Keywords: Family, Constitutional Court, legislation, moral, Amoris Laetitiae.

\section{La reconnaissance de nouvelles formes de famille en Colombie: défis pastoraux et moraux à la mission évangélisatrice de l'Église à la lumière du synode et d" "Amoris Laetitia"}

\section{Résumé}

L'article que nous présentons aux lecteurs est le résultat d'une recherche sur la famille : sa nature, sa réalité, sa classification et typologie ; ainsi que le développement de la jurisprudence de la Cours Constitutionnelle de Colombie, qui a donné lieu à un processus d'évolution du concept de la famille et les nouvelles formes de famille, reconnues dans le système juridique du pays. Il s'occupe également de la position de l'Église contre le concept de la famille et de ses nouvelles formes. Les défis juridiques, éthiques, culturels, moraux pour le pays et pour l'Église dans son travail d'évangélisation et d'humanisation, depuis le Synode de la Famille 2014 - 2015 et surtout depuis l'Exhortation Apostolique "Amoris Laetitia" du Pape François.

Mots clés: Famille, Cours Constitutionnelle, législation, moral, Amoris Laetitia. 


\section{Problema:}

Cuál ha sido la evolución histórica del concepto de familia y de las nuevas formas de familia en Colombia, como resultado de las Sentencias y de la jurisprudencia de la Corte Constitucional entre 1991 y 2015. Y ¿qué retos morales y pastorales representa esta realidad para la misión de la Iglesia?

\section{Metodología:}

La metodología seguida en la investigación es de orden deductiva para a un análisis histórico - crítico de la evolución del concepto de familia y el surgimiento de las nuevas formas de familia reconocidas en la sociedad y por el Estado, como fruto de la jurisprudencia de la Corte Constitucional Colombiana. De la misma manera se abordó la visión y doctrina de la Iglesia sobre la familia. Mediante revisión y análisis documental de Sentencias de la Corte y documentos de la Iglesia.

\section{Objetivo:}

Identificar el proceso evolutivo que ha experimentado el concepto de 'familia' y las nuevas formas de familia en Colombia, y los retos morales y pastorales que estas nuevas realidades representan para la misión de la Iglesia.

\section{Introducción}

La familia como institución social, jurídica y eclesial ha experimentado grandes transformaciones tanto en su identidad, integración y expresión; como resultado de cambios sociales, culturales, políticos y jurídicos. Lo que ha originado que el concepto 'familia' se haya modificado y en algunos casos se haya ampliado, al tiempo que han surgido nuevas expresiones de la vida y naturaleza familiar, conocidas como nuevas formas de familia reconocidas en el orden legal y jurisprudencial, como sujetos de derechos y deberes y actores sociales. Este hecho social plantea grandes interrogantes a grandes sectores de la sociedad así como a las enseñanzas y a la misión de la Iglesia.

Se aborda el tema desde la sociología, el derecho y la teología pastoral. Con el propósito de analizar el proceso evolutivo que el concepto de familia y las nuevas 
formas de familia ha experimentado en la legislación Colombiana, fruto de las Sentencias de la Corte Constitucional. De igual manera se presenta la visión de la Iglesia acerca de la familia y los retos morales y pastorales que esta tiene en las nuevas expresiones, plantea a la misión de la Iglesia, en la perspectiva del Sínodo de Familia y de la Exhortación Apostólica "Amoris Laetitia" del Papa Francisco.

En la primera parte se hace un breve recorrido por los conceptos, tipologías y rasgos evolutivos de la familia; en la segunda se analiza la evolución constitucional y jurisprudencial que ha tenido el concepto en Colombia por las sentencias de la Corte Constitucional. En un tercer momento se presenta la visión de la Iglesia sobre la familia: identidad, misión y problemática a la luz de Amoris Laetitia. En el cuarto apartado se presentan algunos retos éticos, morales y pastorales que se consideran y cómo los nuevos conceptos de familia manifiestan a la misión evangelizadora de la Iglesia. Y se finaliza con las conclusiones generales.

\section{Concepto, evolución y tipología de la familia.}

La familia como institución básica de la sociedad y como núcleo esencial de la misma, enfrenta en la actualidad grandes interrogantes entorno a su identidad y debe responder a los cuestionamientos de muchos sectores sobre su alcance, naturaleza y función en la sociedad. Pues no cabe duda que su importancia va más allá de una mera reunión de personas que deciden asociarse para compartir de manera temporal o indefinidamente la convivencia en un lugar determinado; y del mismo modo su necesidad no se limita a garantizar solamente la existencia y reproducción de la especie humana, o la estabilidad emocional y sentimental de sus integrantes, pues también comprende una serie de experiencias diversas en las que se desarrollan y comunican valores, conocimientos y pautas morales de conducta que, condicionadas por las costumbres y estereotipos socio-culturales, se transmiten de generación en generación, se adaptan y evolucionan. Para Virginia Gutiérrez de Pineda y Patricia Vila de Pineda (1988):

[...] la familia con su conjunto de valores y su estructura, es suma integrada de influjos y presiones que emanan del todo institucional y de la cultura. Lo que se ha venido reflejando en un devenir histórico, resultante de un ambiente social creado por el total institucional: economía, religión, socialización, poder político, ley, etc., y por un cerco cultural tratando la familia de adecuarse a estos influjos institucionales. (p. 29)

Así pues, la familia es algo más que una simple forma de organización social voluntaria, afectiva y hasta restringida, su concepto comprende una variedad, 
aún no determinada de formas y modos de conformación, situación que dificulta la elaboración de un concepto universal o un modelo definitivo. Tal y como lo plantea De León Willis (2012), la familia comprende una realidad social diversa que con el tiempo ha dejado de ser inmutable, invariable e inalterable, pasando de su forma tradicional de conformación heterosexual (padre, madre e hijos), hasta las más diversas formas de convivencia legitima posibles y controvertidas.

En igual sentido, Vincenzo Ferrari (2012) afirma que la familia es una institución social de gran importancia para la sociología, cuyo alcance y definición varían según la perspectiva metodológica o ideológica desde donde se analice; verbigracia, desde la perspectiva antropológica se pueden observar algunas tipologías y conceptos de familia como es el caso de las familias matrilineales, patrilineales, monogámicas, poligámicas, monoparentales y de unión voluntaria; la familia matrilineal ${ }^{1}$, por ejemplo, corresponde a aquellas donde se presentan relaciones sexuales promiscuas, y se da preeminencia a la mujer y su descendencia, sin consideración a la paternidad natural; la familia patrilineal, por el contrario, le da preeminencia a la paternidad; las familias monogámicas y poligámicas, responden más a un rasgo de exclusividad y unidad en la familia; la familia monoparental por su parte, se encuentra ligada a una concepción más nuclear y restringida de la familia que puede incluir parejas homosexuales y heterosexuales, con o sin prole, y; la unión voluntaria corresponde a un vínculo de unión libre de personas que deciden compartir bajo el mismo techo una comunidad de vida, unidos por relaciones afectivas, no sexuales.

Como institución, la familia también ha sido descrita como un sistema que regula, estabiliza y estandariza las relaciones sexuales, la procreación y la satisfacción de necesidades básicas entre las personas, su forma tradicional más propagada en el mundo occidental es la unión monógama de un hombre y una mujer, que como pareja conviven al cuidado de sus hijos dentro de un mismo lugar, denominado hogar, asimismo y dentro de la familia se encuentran otras instituciones como el noviazgo, el matrimonio, el cuidado de los niños, el parentesco por afinidad, entre otras, de acuerdo con Joseph H. Fichter (1975).

Desde los inicios de la Republica de Roma (siglo V a. C.), la familia ha gozado de una importancia social y política indiscutible. Durante la época de Justiniano, los romanos comprendían a la familia o domus como una reunión de personas bajo la autoridad del manus o también jefe único, la cual estaba reservada al paterfamilias, una especie de autoridad paternal bajo la cual se encontraban sometidos

1 Hace referencia al predominio de la línea materna y sus descendientes directos. 
todos sus descendientes incluyendo la mujer (in manu) quien entre otras cosas ocupada el mismo lugar de la hija (loco filiae), convirtiéndose este, en un modelo de familia con régimen patriarcal, en el cual el paterfamilias ostenta el poder absoluto de conformar sus descendientes, excluirlos a través de la emancipación, o hacer ingresar a una persona mediante la figura de la adopción, tal y como lo plantea Eugéne Petit (1976).

Los romanos consideraban dos tipos de parentesco dentro de la familia, los cognados y los agnados, de acuerdo con Eugéne Petit (1976) los cognados correspondían al parentesco natural de los padres con sus descendientes en línea directa sin distinción de sexo, mientras que los agnados se constituían dentro de una relación de parentesco civil, bajo la autoridad del paterfamilias, sin que fuera necesario el vínculo consanguíneo, no obstante, esta forma de parentesco incluía a los hijos adoptados y a la mujer.

En una perspectiva histórico evolutiva, Friedrich Engels (1884) señalaba que la familia ha tenido varias fases o etapas identificables que en un orden más o menos cronológico, corresponden a la familia consanguínea, la sindiásmica ${ }^{2}$, la punalúa y la monogámica, las cuales se podrían comprender de la siguiente forma: la familia consanguínea, referida aquella en la que los descendientes de una pareja en cada una de cuyas generaciones sucesivas todos fuesen entre sí hermanos y hermanas y casi al mismo tiempo, maridos y mujeres unos de los otros; la familia punalúa, caracterizada por un proceso de exclusión gradual en las relaciones sexuales entre hermanos hasta llegar a los colaterales carnales, de segundo y de tercer grado; la familia sindiásmica, también denominada como régimen de matrimonios por grupos, donde prevalecían las preferencias individuales del hombre, y se castigaba con crueldad la infidelidad de la mujer, en tal sentido el hombre ejercía un poder dominante casi absoluto sobre su familia; y finalmente la familia monogámica, la cual se caracteriza por tener mayor solidez y lazos conyugales más fuertes, la que conlleva desde luego la paternidad indiscutible.

Rico de Alonso (1999) plantea que la familia se encuentra organizada en dos tipologías, una según el parentesco y otra según sus funciones, de acuerdo al parentesco, se divide en tres categorías, que son: la unipersonal, la nuclear y la extendida; de acuerdo a sus funciones se dividiría en otras tres categorías: conyugalidad, reproducción y supervivencia. La familia unipersonal, es aquella clase de organización de familia integrada exclusivamente por un jefe único; la

2 Esta forma de organización de la familia, permitía ciertos privilegios en favor del hombre. 
familia nuclear, es aquella conformada por una pareja de conyugues, con o sin hijos, y con un perfil cada vez más restringido, caracterizada por la mutabilidad y trascendencia social, como es el caso de los países del primer mundo donde se habla de familias nucleares monoparentales, o con parejas homosexuales y heterosexuales; la familia extendida, es aquella donde se incluyen otros parientes o incluso amigos y trabajadores como parte del componente familiar. La conyugalidad es entendida como la "convivencia vitalicia para organizar la sexualidad y garantizar societal y familiarmente la legitimidad" (p. 111). Por otro lado, la reproducción constituye una función natural, básica y esencial para la preservación de la especie, sin ser este un propósito determinante para la conformación de una familia.

En las diversas regiones, países y continentes a lo largo de los siglos, la estructura familiar, su organización y funcionalidad en la sociedad ha experimentado procesos de transformación, adaptación y asimilación cultural, religiosa, política y socio-jurídica. Para responder en muchos casos a procesos de colonización o asimilación cultural. En la actualidad, dichas transformaciones responde a la llamada globalización cultural y, que trata de establecer estándares en materia de estructura jurídica y social; motivada por el reconocimiento creciente de los derechos humanos y el compromiso de los países por reconocerlos en el ordenamiento constitucional, promoverlos y respetarlos.

Sin embargo, las tradiciones culturales y religiosas siguen primando en muchos países a la hora de constituir las relaciones matrimoniales y de familia, sobre todo en países del tercer mundo con altos índices de pobreza y bajos niveles de educación, especialmente en el caso de las mujeres. Se dan, por ejemplo, matrimonios concertados por los padres o parientes en muchas partes del mundo, sea por motivos religiosos, culturales o económicos. Lo que también afecta la estructura e identidad de dichas familias.

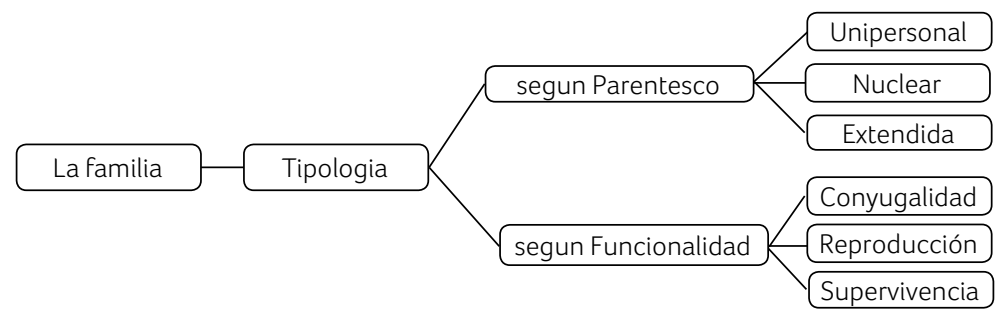

Fuente: basado en la tipología presentada por Ana Rico de Alonso (1999), en su artículo: formas, cambios y tendencias en la organización familiar en Colombia. 
Patricia Arés Muzio define estructuralmente la familia y tiene en cuenta criterios como: 1) consanguíneos con lo cual se considera familia a todas aquellas personas con vínculos conyugales o consanguíneos. 2) cohabitacionales constituidas por personas que cohabitan bajo un mismo techo, unidos relaciones espacio-temporales; independientemente de los lazos o vínculos conyugales o consanguíneos. Y 3) afectivos, conformadas por personas que tienen un vínculo de relaciones afectivas estables. Es necesario resaltar que en el contexto colombiano e internacional esta clasificación ha tenido gran influencia en la elaboración de políticas públicas y leyes, que garantizan el reconocimiento de identidades y nuevas formas de familia y de derechos a las mismas.

En Colombia la conformación, identidad, estructura y organización de la familia ha experimentado cambios profundos en línea con las transformaciones culturales y sociales a partir de 1950. El Censo Nacional de Población que se adelantó en 1978 junto con la encuesta a hogares, reveló que más de la mitad de la población nacional, durante el periodo comprendido entre 1978 y 1993, predominaba la familia nuclear tradicional, el 40\% compartían la convivencia con parientes y otros, y menos del 7\% de la población conformaba su familia de forma unipersonal. Un panorama que se suma al hecho de que la familia, hasta antes de la Constitución de 1991 solo era reconocida como tal, siempre y cuando hubiese sido constituida en la ritualidad del matrimonio. Esto explica porque las relaciones entre concubinos no producían efectos civiles y los derechos y obligaciones de los hijos extramatrimoniales eran tan limitados (Parra Bolívar, 2005)

En la Encuesta Nacional de Demografía y Salud -ENDS 2005- 2010 se analizan las transformaciones familiares en las regiones del país. Entre las transiciones que muestran las estadística están: 1) incremento de la familia nuclear, 2) estabilidad de la familia nuclear completa (ambos padres e hijos): se mantuvo estable $(35 \%)$; 3) aumento de los hogares monoparentales con mujeres cabeza de familia entre 3 y 6 puntos porcentuales, proporción en las zonas urbanas $(36,7 \%)$ que en las rurales $(25,4 \%) ; 4)$; disminución de la familia extensa en 2005 representaba el $33,6 \%$ y en 2010 , el 30,9\%; 5) las familias compuestas se reducen del $5,4 \%$ a $4,2 \%$ entre 2005 y 2010; 6); las unipersonales al 12\%. La familia extensa colombiana (padres, hijos solteros y otros parientes diferentes), se redujo del 33,6\% en 2005 al 30,9\% en 2010. Pero se comprueba el aumento de las familias compuestas por parejas sin hijos que pasó de 6,6\% en 2005 a 7,8\% en 2010; la familia unipersonal va en aumento en todo el país al pasar de 7,7\% en 2005 al 9,5\% en 2010.

Finalmente, se debe tener en cuenta que existen conceptos comunes a nivel social, jurídico y hasta religioso, que han identificado a lo largo de la historia el ser o hacer familia, entre otros: institución social, grupo social, unidad social, núcleo 
social, convivencia social, devenir social, institución básica, célula básica, primera y decisiva escuela, grupo de referencias, formación de los hijos, preparación para la vida, personas emparentadas entre sí, grupo humano, estabilidad de relaciones, comunicación, satisfacción de necesidades, conjunto de personas que viven relaciones plurales y diversas, como producto de la construcción social constante en la sociedad mediada por la cultura, los medios de comunicación y la globalización.

\section{El Derecho de familia en Colombia y las nuevas formas de familia reconocidas: un proceso evolutivo y garantísta.}

En Colombia no existe un código independiente o un sistema autónomo de regulación legal dirigido exclusivamente para la familia, como si ocurre con el código de la infancia y la adolescencia, Ley 1098 del 2006, aunque este código hace referencia explícita también a la protección de la familia. No obstante, el Código Civil Colombiano, contiene disposiciones sobre obligaciones y derechos que regulan las relaciones de familia, tal y como se observa en los libros primero y cuarto de este ordenamiento legal (Monroy Cabra, 2007).

De igual forma, a partir de la Constitución Política de 1991, la familia es promovida a la forma de derecho constitucional, no precisamente fundamental, pero si susceptible de tutela en circunstancias especiales ${ }^{3}$, como cuando se vean amenazados los derechos de los menores de edad. El artículo 42 del inicio del Capítulo II que trata sobre los Derechos Sociales, Económicos y Culturales de la Constitución Política de Colombia dice que:

La familia es el núcleo fundamental de la sociedad. Se constituye por vínculos naturales o jurídicos, por la decisión libre de un hombre y una mujer de contraer matrimonio o por la voluntad responsable de conformarla. El Estado y la sociedad garantizan la protección integral de la familia. La ley podrá determinar el patrimonio familiar inalienable e inembargable. La honra, la dignidad y la intimidad de la familia

3 Considerando que la acción de tutela como mecanismo constitucional preferente, de acuerdo al artículo 86 de la Constitución Política, opera exclusivamente para la protección de derechos fundamentales que se vean amenazados o vulnerados por la actuación, acción u omisión de la autoridad o de los particulares, que sea de tal magnitud que produzca un perjuicio irremediable.

Por su parte, la Corte Constitucional mediante sentencia T-572 de 2009, precisó que: "La preservación de la unidad familiar presenta una dimensión iusfundamental, amparable en sede de tutela, en tanto que aquella de contenido exclusivamente prestacional quedará sometida a los avances legislativos, al igual que al diseño y ejecución de políticas públicas encaminadas a su preservación". 
son inviolables. Las relaciones familiares se basan en la igualdad de derechos y deberes de la pareja y en el respeto recíproco entre todos sus integrantes. Cualquier forma de violencia en la familia se considera destructiva de su armonía y unidad, y será sancionada conforme a la ley. Los hijos habidos en el matrimonio o fuera de él, adoptados o procreados naturalmente o con asistencia científica, tienen iguales derechos y deberes. La ley reglamentará la progenitura responsable. La pareja tiene derecho a decidir libre y responsablemente el número de sus hijos, y deberá sostenerlos y educarlos mientras sean menores o impedidos. Las formas del matrimonio, la edad y capacidad para contraerlo, los deberes y derechos de los cónyuges, su separación y la disolución del vínculo, se rigen por la ley civil. Los matrimonios religiosos tendrán efectos civiles en los términos que establezca la ley. Los efectos civiles de todo matrimonio cesarán por divorcio con arreglo a la ley civil. También tendrán efectos civiles las sentencias de nulidad de los matrimonios religiosos dictadas por las autoridades de la respectiva religión, en los términos que establezca la ley. La ley determinará lo relativo al estado civil de las personas y los consiguientes derechos y deberes. (Constitución Nacional, art. 42)

A este mandato, se le suman las interpretaciones que ha hecho la Corte Constitucional, desde 1991, sobre el alcance y la naturaleza jurídica del derecho a la familia en Colombia, igualmente sobre las obligaciones, derechos y deberes de sus miembros legítimos, frente a ellos mismos, con los demás, y respecto a la complejidad de situaciones que se desprenden de ella, bien como consecuencia de la convivencia permanente y simultánea, o bien como resultado de la interacción problemática que a veces se genera en su interior.

En Colombia, el concepto de familia ha sufrido transformaciones importantes, particularmente para el periodo comprendido entre el 2007 y 2011, donde la Corte Constitucional reconoció la igualdad de derechos para las parejas del mismo sexo, al equiparar, casi en su totalidad, los derechos que eran exclusivos de las parejas heterosexuales (De León Willis, 2012), especialmente en lo atinente a beneficios del sistema general de Salud y pensional.

Las sentencias de la Corte Constitucional sobre la familia, en orden a garantizar los derechos humanos de personas o grupos han originado por una parte y consolidado por otra, toda una serie de procesos culturales, sociales y jurídicos, que han transformado el concepto y las relaciones de familia, desde el desarrollo constitucional a partir de 1991. Un claro ejemplo lo tenemos en sentencia de tutela 
T-523 de 1992, en la que se tutela que los derechos de una persona a visitar a su hijo desarrolla el concepto de familia y sus relaciones desde el reconocimiento de los derechos y deberes de los miembros. Señala en uno de sus apartes lo siguiente:

Dentro de la concepción individualista, la unidad de familia aparece como el equilibrio entre la libertad de los cónyuges y las exigencias concretas de dicha unidad, en función de los intereses individuales de sus miembros. Supone, pues, una paulatina privatización de las relaciones familiares dentro de la cual se valora la libertad de aquellos tanto dentro de la convivencia como en el ejercicio del derecho a la separación, cuando la primera no esté ya respaldada por la perduración del consentimiento. En una concepción solidarista, por el contrario, se reconoce que la privatización no puede llevarse hasta el punto de perjudicar a los sujetos más débiles o a la sociedad civil o perjudicar la estabilidad de la familia como núcleo fundamental de la sociedad y la suerte misma de los niños, los cuales son titulares privilegiados de un interés jurídico superior. Una de cuyas manifestaciones es, hoy precisamente, el derecho constitucional prevalente a tener una familia y no ser separado de ella. (Corte Constitucional, T-523)

Esta concepción del interés prevalente y superior del menor frente a la familia, implica otro conjunto de deberes importantes en cabeza, no solo de sus propios padres sino también del Estado, cualquiera que sea la procedencia de los hijos, pues lo propio sucede también con los hijos adoptados, quienes gozan de iguales derechos que los hijos naturales frente a la ley y a la Constitución; en efecto, la sentencia T-292 de 2004 de la Corte Constitucional señala que el derecho a la familia:

[...] cuenta con una serie de garantías constitucionales adicionales que refuerzan la necesidad de preservarlo en todo caso, a saber, la consagración de la familia como la institución básica de la sociedad, digna por ende del amparo estatal; la prohibición de molestar a las personas -incluidos los niños- en su familia; y la protección de la intimidad familiar. Tanto el derecho a tener una familia y no ser separado de ella, como las garantías adicionales en cuestión, forman parte de las obligaciones internacionales del Estado colombiano en materia de derechos humanos. El derecho de los niños a tener una familia y no ser separados de ella tiene una especial importancia para los menores de edad, puesto que por medio de su ejercicio se materializan numerosos derechos constitucionales diferentes, que por lo tanto dependen de él para su 
efectividad: es a través de la familia que los niños pueden tener acceso al cuidado, el amor, la educación y las condiciones materiales. (Corte Constitucional, T-292)

Otro tipo de obligaciones y derechos que se originan por formar parte de una familia, es el de solidaridad, tal y como se observa en la sentencia T-1079 de 2001, en los siguientes términos: “La Constitución, establece el principio de solidaridad social como parte fundante del Estado social de derecho, articulo 95 numeral 2, según el cual es deber de todas las personas responder con acciones humanitarias ante situaciones que pongan en peligro la vida o la salud de las personas, y cuya primera manifestación, sin lugar a dudas, ha de darse entre los miembros de la familia, en caso de necesidad de uno de sus integrantes. (...)".

En sus inicios, la Corte Constitucional, presentó una concepción restrictiva de familia, como se puede observar en las sentencias T-190 de 1993 y T-012 de 1995, respectivamente, sobre todo cuando se refiere a su conformación: “El vínculo constitutivo de la familia - matrimonio o unión de hecho - es indiferente para efectos del reconocimiento de este derecho. El factor determinante para establecer qué persona tiene derecho a la sustitución pensional en casos de conflicto entre el cónyuge supérstite y la compañera o compañero permanente es el compromiso de apoyo afectivo y de comprensión mutua existente entre la pareja al momento de la muerte de uno de sus integrantes".

En efecto, la Corte llego a considerar que la familia solo se podía conformar siempre y cuando estuviera integrada desde el matrimonio civil o religioso, o desde la unión de hecho. Sin desconocer, claro está, que en algunos casos una de estas dos circunstancias eran exigidas por la ley para el reconocimiento de derechos pensionales como la sustitución pensional o la pensión de sobrevivientes que solo procede, con el cumplimiento de ciertos requisitos. Hasta el 2006, solo amparaba y reconocía derechos pensionales a la familia nuclear heterosexual, constituida por la unión de un hombre y una mujer, como se evidencia en el siguiente extracto de la sentencia T-349 de 2006, así:

Podría argumentarse que, no obstante que el sistema de seguridad social haya previsto una especial protección a la familia, se produce una lesión del principio de igualdad porque dicha protección ampara al cónyuge o compañero o compañera permanente en la pareja heterosexual, independientemente de la existencia de hijos, pero se niega a las parejas homosexuales. (Corte Constitucional, T-349) 
En este sentido, para De León Willis, J. (2012), las consideradas formas de familias emergentes, comprenden precisamente aquellas que son conformadas por parejas del mismo sexo, las cuales, terminaron por ser reconocidas por la propia Corte Constitucional a partir de la sentencia C- 075 de 2007, particularmente las que eran constituidas mediante unión marital de hecho.

Esta cuestión tuvo un mayor desarrollo en la sentencia C-577 de 2011, donde la Corte Constitucional, amplía el alcance del concepto de familia, al expenderlo a las parejas del mismo sexo con todos los derechos y responsabilidades establecidos en el artículo 42 de la Constitución Política; como se observa en el siguiente extracto:

[...] se ha concluido que el principio democrático no puede avalar "un consenso mayoritario que relegue a los homosexuales al nivel de ciudadanos de segunda categoría" y que el principio de igualdad se opone, de manera radical, a que a través de la ley, por razones de orden sexual, se subyugue a una minoría que no comparta los gustos, hábitos y prácticas sexuales de la mayoría". Fuera de la aproximación a la homosexualidad desde la perspectiva de la persona individual y desde el punto de vista del grupo minoritario tradicionalmente desprotegido, últimamente se ha afianzado en la jurisprudencia la consideración de la pareja integrada por personas del mismo sexo, "puesto que hoy, junto a la pareja heterosexual, existen -y constituyen opciones válidas a la luz del ordenamiento superior- parejas homosexuales", cuya efectiva existencia supone, como en el caso de la pareja heterosexual, "una relación íntima y particular entre dos personas, fundada en el afecto, de carácter exclusivo y singular y con clara vocación de permanencia. (Corte Constitucional, C-577)

Para concluir este segundo apartado se puede afirmar que la Corte Constitucional en las diferentes sentencias sobre el tema de la familia, los derechos de la misma y de sus miembros, entre 1991 y 2011 ha evidenciado un desarrollo evolutivo, en consonancia con el derecho internacional público y privado. Al partir del reconocimiento de que Colombia es un Estado, social de derecho, que ha ratificado la Declaración Universal de los Derechos Humanos, la Convención Americana de Derechos Humanos, la convención de los derechos del niño y de la mujer, entre otras. Y que por lo tanto tiene la responsabilidad de garantizar y viabilizar dichos derechos, para adecuar la legislación al Derecho Inter-americano e Internacional de los Derechos Humanos. 


\section{La evangelización de la familia y de las nuevas formas de familia en Colombia en la perspectiva de Amoris Laetitia: "Acompañar, discernir e integrar"}

Afrontar como Iglesia el tema de la evangelización y de la promoción humana integral de la familia y de las nuevas formas de familia en Colombia, implica grandes opciones, reflexiones y compromisos teológicos y pastorales. Exige partir de la realidad que vive la familia y las familias, en sus diferentes identidades, expresiones, transformaciones y relaciones ad intra y ad extra entre sus miembros con y la comunidad. Aquí las ciencias sociales harán grandes aportes a este estudio, ya que nos permitirán conocer la realidad de la familia para no tratar el tema desde los ideales y concepciones tradicionales. En este sentido es necesario privilegiar el ser, sobre el deber ser y acercarse a la familia y a las nuevas formas de familia reconocida por el Estado, y que son fruto de profundos cambios antropológicos, culturales, sociales, económicos, jurídicos, etc., originados entre otros factores, por la influencia creciente de los medios de comunicación y la globalización de la cultura. Sería un error grave abordar el tema de la familia y organizar programas y proyectos desde ideales y definiciones, que nada tiene que ver con la realidad que vive y expresa la familia en la sociedad Colombiana y mundial.

Es de resaltar que durante los dos años 2014 - 2015, en los que el Sínodo abordó el tema de la familia, realizó un profundo análisis integral de la situación, de la problemática y aciertos de la familia actual, desde los aspectos culturales, sociales, antropológicos, bíblicos y teológicos. No sin grandes debates entre las diferentes tendencias: la que partía de definiciones y conceptos tradicionales, y la que partía de la realidad y de opciones teológicas, morales y pastorales en diálogo con el mundo real. Dicha comprensión ayudó a establecer lineamientos pastorales para abrir a la Iglesia a un diálogo con las familias en sus formas y expresiones actuales, en sus necesidades y realizaciones, como sujetos de evangelización y actores privilegiados en la misma, y como agentes de la transformación de la sociedad en perspectiva humanizadora.

En Amoris Laetitia se evidencia que como fruto su ministerio pastoral y del Sínodo, el Papa Francisco promueve un proceso de acogida y acompañamiento a todas las familias, en sus realidades concretas, de manera especial a las que atraviesan dificultades de toda índole, principalmente a las que se encuentran en situación irregular dentro de la Iglesia. El Papa invita a entrar en un proceso de discernimiento en diálogo profundo entre fieles y pastores, desde la realidad de las personas y de las familias, en el contexto eclesial, social, cultural y político. En orden a la inserción de dichas familias, en la vida y misión de la Iglesia. Es un 
llamado a "lógica de la misericordia pastoral". Y al discernimiento pastoral desde la Palabra de Dios que ilumina la realidad y la vida cotidiana en todas sus dimensiones y a ser dóciles al Espíritu Santo para hacer presentes las exigencias de verdad y caridad del Evangelio, desde la tradición y el magisterio de la Iglesia, pero sobre todo desde la práctica de Jesús en su acogida al pobre y al pecador. Afrontando las situaciones de fragilidad, complejas o irregulares que padecen muchas familias que buscan ayuda y acompañamiento pastoral mediante la gradualidad en la pastoral (AL, 293-295).

En esta línea, el Papa Francisco en Amoris Laetitia en el capítulo 8, (Numerales 252 - 270). Asume como una necesidad y opción, el acompañamiento a los casos de fragilidad y de alejamiento del ideal cristiano de la familia y del matrimonio, por eso pide "acompañar, discernir e integrar", en la "lógica de la misericordia pastoral" estas nuevas realidades. Sin los juicios generalizados para invitar a los agentes pastorales a estar atentos desde el ejercicio de la misericordia pastoral a la manera en que las personas viven y asumen su condición.

Frente a situaciones complejas como los divorciados vueltos a casar expresa: "los bautizados que se han divorciado y se han vuelto a casar civilmente deben ser más integrados en la comunidad cristiana" claramente para evitar "cualquier ocasión de escándalo", pero sin que se sientan excomulgados y abriendo la posibilidad a algunos servicios eclesiales. Una integración necesaria también para "la educación cristiana de sus hijos". Es muy positivo el hecho de que se promueva el análisis caso por caso de cada situación compleja y se proponga un itinerario de acompañamiento y de discernimiento que orienta a estos fieles a la toma de conciencia de su situación ante Dios, Sin pretender ser la conciencia de los fieles o manipularla. En este sentido afirma que: “La conversación con el sacerdote, en el fuero interno, contribuye a la formación de un juicio correcto sobre aquello que obstaculiza la posibilidad de una participación más plena en la vida de la Iglesia y sobre los pasos que pueden favorecerla y hacerla crecer". Un discernimiento que "no podrá jamás prescindir de las exigencias de verdad y de caridad del Evangelio propuesto por la Iglesia".

Aunque el eje central de Amoris Laetitia es el matrimonio y la familia, también aborda la realidad de personas que no están casadas. Entre ellas, los padres y madres solos, las viudas y viudos, los hombres y mujeres solteros. Afirmando que todos son hijos de Dios, que tienen una historia familiar y lazos de amor con sus parientes y amigos, algunos en situaciones familiares difíciles y dolorosas.

Frente a las uniones homosexuales equiparadas en muchos países a matrimonios, el Papa, según las posiciones del sínodo y la relación final del mismo de 2015, reafirma que la enseñanza de la Iglesia es clara: el matrimonio es entre 
un hombre y una mujer, y las uniones homosexuales no se pueden equiparar al matrimonio cristiano. (AL, 251). Además que "no existe ningún fundamento para asimilar o establecer analogías, ni siquiera remotas, entre las uniones homosexuales y el designio de Dios sobre el matrimonio y la familia".

De la misma manera que recordó que "la Iglesia hace suyo el comportamiento del Señor Jesús que en un amor ilimitado se ofrece a todas las personas sin excepción" (AL, 250). Y que "toda persona, independientemente de su tendencia sexual, ha de ser respetada en su dignidad y acogida con respeto" para evitar toda forma de agresión y violencia. Para alentar a los fieles a ayudar a las personas con tendencia homosexual a "comprender y realizar plenamente la voluntad de Dios en su vida".

Para hacer presente en las prácticas y en los pronunciamientos, cómo Iglesia muestra esta lógica de la misericordia pastoral desde un proceso constante de acompañamiento y discernimiento con las familias en dificultades, el Papa Francisco en "Amoris Laetitia", capítulo 8 numerales 293 - 295, presenta el principio de la gradualidad pastoral como una herramienta para abordar y superar las dificultades pastorales que viven muchas familias en la actualidad, al no poder configurarse plenamente con el ideal cristiano. En este sentido, el capítulo 3 de la relación final del Sínodo 2015 y el capítulo 8 de "Amoris Laetitia" invitan a recordar las palabras del Papa "a menudo, la tarea de la Iglesia asemeja a la de un hospital de campaña" (AL, 291). Frente al discernimiento pastoral ante situaciones complejas y consideradas "irregulares", el Papa afirma que "hay que evitar los juicios que no toman en cuenta la complejidad de las diversas situaciones, y es necesario estar atentos al modo en que las personas viven y sufren a causa de su condición" (AL, 296). Con lo que se invita a integrar a todos y a ayudar a cada persona a encontrar su propia manera de participar en la vida y misión de la Iglesia, "para que se sienta objeto de una misericordia «inmerecida, incondicional y gratuita»" (AL, 297).

El principio de gradualidad, recuerda que es necesario tener en cuenta que la ética cristiana nace y se desarrolla del encuentro vivo, dinámico y creativo del Evangelio con las personas concretas y con las diversas culturas; por lo tanto, los principios que orientan la vida ética y moral de los fieles y de todos los miembros de la Iglesia, no son estáticos, sino que evolucionan y encuentran también nuevas expresiones. De ahí que el discernimiento, el acompañamiento pastoral y las implicaciones del derecho canónico, deben partir del hecho que: "la innumerable diversidad de situaciones concretas (...) puede comprenderse que no debería esperarse del Sínodo o de esta Exhortación una nueva normativa general de tipo canónica, aplicable a todos los casos. Solo cabe un nuevo aliento a un responsable 
discernimiento personal y pastoral de los casos particulares, que debería reconocer, dado que el grado de responsabilidad no es igual en todos los casos, las consecuencias o efectos de una norma no necesariamente deben ser siempre las mismas" (AL, 300). "Comprender las situaciones excepcionales nunca implica ocultar la luz del ideal más pleno ni proponer menos que lo que Jesús ofrece" (AL, 307).

El tema de la gradualidad fue abordado por el concilio Vaticano II, que convocó a una profunda renovación en la vida cristiana, en las instituciones eclesiales, en las prácticas y disciplinas teológicas, como lo es la ética teológica. E invita a que se estudien profundamente las situaciones por las que atraviesa la humanidad en la actualidad y se presenten respuestas a las mismas (Cf. Gaudium et Spes, 1-10). Y también por el Papa Juan Pablo II la encíclica Veritatis Splendor que se refiere a la ética cristiana invita a: "buscar y encontrar la formulación de las normas morales universales y permanentes más adecuada a los diversos contextos culturales, más capaz de expresar incesantemente la actualidad histórica y hacer comprender e interpretar auténticamente la verdad" (N 53).

De igual manera, El Papa Juan Pablo II en la exhortación apostólica Familiaris Consortio, de noviembre de 1981, expone el principio de gradualidad cuando habla de la misión de la familia en el mundo actual, en el numeral 34 afirma: " $E l$ ser humano es un ser histórico, que se construye día a día con sus opciones numerosas y libres; por esto él conoce, ama y realiza el bien moral según diversas etapas de crecimiento". Y lo complementa en el número 9 cuando dice:

Se pide una conversión continua, permanente, que, aunque exija el alejamiento interior de todo mal y la adhesión al bien en su plenitud, se actúa sin embargo concretamente con pasos que conducen cada vez más lejos. Se desarrolla así un proceso dinámico, que avanza gradualmente con la progresiva integración de los dones de Dios y de las exigencias de su amor definitivo y absoluto en toda la vida personal y social del hombre. (FC, 9)

En la reflexión y en la práctica del acompañamiento y de la pastoral familiar, es necesario tener en cuenta que la Iglesia defiende que el principio de la gradualidad no significa gradualidad de la ley, sino el reconocimiento de que la vida cristiana constituye un proceso de conversión y crecimiento en la santidad progresivos, una invitación al esfuerzo por crecer en fidelidad al Evangelio. Plantea grandes oportunidades pastorales así como retos doctrinales y pedagógicos, y que es en el diálogo con las diversas culturas y formas de pensamiento, entre el saber teológico y las ciencias humanas, que la misma Iglesia ha aceptado que la conversión y la santificación del hombre es un proceso de crecimiento constante 
en la configuración con Jesucristo, ideal de la ética y de la moral cristiana. Proceso, compromiso, opción que no se da de un momento para otro, sino como un "camino progresivo". Tal como lo asume el sínodo de la familia de 1980, con el que se invita a realizar la reflexión necesaria para que la Iglesia pueda desarrollar la "pedagogía de la gradualidad", en su tarea de acompañar a las personas y a las comunidades en su camino de configuración con el ideal de la persona: Jesús.

\section{Desafíos éticos, morales y pastorales del reconocimiento de las nuevas formas de familia a la misión de la Iglesia en Colombia.}

La familia colombiana y el concepto 'familia' desde mediados del siglo XX ha experimentado profundos cambios en su identidad, en su expresión y en su problemática, producidos por la urbanización, el conflicto armado, el empobrecimiento de la población, la educación y el compromiso del Estado con la promoción de los Derechos Humanos, los medios de comunicación y la globalización, entre otros aspectos. Sociológica y jurídicamente se acepta hoy como un hecho que tanto la realidad como el concepto de familia viven un proceso de evolución generado por transformaciones sociales y culturales, dinámicas alentadas por una cultura globalizada. En la actualidad, desde muchos sectores del pensamiento, de la ciencia y la cultura, de la política y la justicia a nivel nacional e internacional se afirma que no hay concepto único ni universal de familia, así como que los roles, los integrantes y las relaciones al interior de la misma son diferentes y socialmente aceptadas.

Son muchos los problemas conceptuales, doctrinales y teológicos que estas nuevas realidades presentan a la misión de la Iglesia. Entre los principales retos éticos, morales y pastorales que la evolución en el concepto de familia y el reconocimiento legal de nuevas formas de familia, plantean a la misión humanizadora y evangelizadora de la Iglesia, se consideran los siguientes como los más relevantes:

1. Frente a su misión Evangelizadora la Iglesia debe tener presente que Colombia es un Estado Social de Derecho, que garantiza la libertad de conciencia, la libertad de cultos; es un Estado laico no confesional. En el cual hay independencia entre el Estado y las diferentes confesiones religiosas. Por lo que la Iglesia Católica ha de estar abierta a un diálogo sincero y constructivo, no con nuestro ideal de sociedad. ideal. independencia entre el Estado y las diferentes confesiones religiosas. críti con la sociedad, con la academia, con la política, pero ante todo 
con el Estado y sus instituciones, para trabajar a todos los niveles en la promoción de la verdad. De la justicia y del bien común.

Es un gran reto a la vida y misión de la Iglesia, el reconocer que el concepto de familia ha evolucionado en la sociedad y en las culturas actuales; y que existen nuevas formas de familia con reconocimiento social, jurídico y constitucional, sujetos de derechos y deberes en la sociedad Colombiana. Y si se quiere evangelizarlos y acompañarlos pastoralmente habrá que partir de su reconocimiento como actores sociales.

2. Los pastores, los fieles y los agentes pastorales en su misión evangelizadora no pueden partir de supuestos u "obviedades", como el que la sociedad Colombiana es católica practicante, conocedora y observante de las normas morales cristiano-católicas y del magisterio eclesial. Dado que en Colombia se evidencia un desconocimiento de los fundamentos de la teología y de vida cristiana. Un gran reto se constituye en la necesidad de implementar un proceso de evangelización permanente, de acercamiento al magisterio y a la doctrina de la Iglesia, que promueva la formación teórico-práctica en derechos y deberes humanos, políticos, sociales y culturales, desde la misma Doctrina Social de la Iglesia.

3. La Evangelización y la pastoral familiar debe partir de la realidad de la familia en todas sus expresiones y en todas las regiones, ambientes, culturas y subculturas del país, para no quedarse anclada en el famoso "DEBER SER" que en muchas ocasiones nada tiene que ver con la realidad que viven las familias en todas sus dimensiones. Se hace necesario establecer una pastoral familiar diferencial que ilumine las nuevas realidades y formas de familia con su problemática, pero también con sus aspectos positivos y sus valores, a la luz del Evangelio y del magisterio eclesial. Para ayudar a las personas que hacen parte estas familias y a las familias mismas, a superar sus dificultades y a crecer en el conocimiento y seguimiento de Cristo. En la línea de "Amoris Laeritia" (293-295) se debe tener en cuenta la gradualidad de la vida cristiana en la acción pastoral. Al reconocer que el ser humano conoce, ama y realiza el bien moral en etapas de crecimiento humano y espiritual; y en esa misma medida asume su compromiso en la sociedad y en la misión de la Iglesia.

4. La práctica de Jesús en su acercarse al hombre y a la mujer concretos, acoge a todos con misericordia y compasión, de manera especial a los considerados pecadores y discriminados social, política, económica y religiosamente; ha de ser la guía a seguir en el encuentro con las personas y con las familias, en su acompañamiento, promoción humana 
integral, evangelización y participación en la vida y misión eclesial. Nuestra misión e identidad como Iglesia es ser "sacramento universal de salvación", permitiendo que las personas, las familias y las culturas se encuentren con Jesús.

5. Es urgente y necesario presentar al hombre de hoy, a las familias y a las culturas el Evangelio como propuesta de humanización integral, y la moral cristiano-católica como una opción de vida feliz y plena. Y no como una carga de negaciones, prohibiciones, prejuicios y miedos, propio de grupos apocalípticos y fundamentalistas. Igualmente la Iglesia debe enfatizar en la belleza y dignidad del matrimonio y de la familia como un lugar de encuentro y comunión, como un medio de realización integral, de felicidad y de vida plena en amor, respeto y fidelidad. Que es en la misma Iglesia y en la sociedad el pilar fundamental de su presente y de su futuro.

6. Hay que tener en cuenta que la Iglesia desde su misión evangelizadora ayuda a formar la conciencia de las personas, no la maneja, ni la remplaza; por lo tanto, en un diálogo respetuoso, sincero y constructivo con la familia, la cultura, la política y la sociedad se hace necesario establecer unos mínimos parámetros éticos y morales que permitan a la familia vivir y realizar su función social, como formadora de personas y ciudadanos. Para promover así el desarrollo humano integral, la convivencia armónica y el bien común. Esto permitirá en la vida eclesial al hombre y a la familia abrirse a los máximos caminos del perfeccionamiento evangélico en la fe, la esperanza y el amor, en orden a la santidad que constituye el ideal supremo de la vida cristiana.

7. Los Pastores, los laicos comprometidos y los fieles en general, así como la Iglesia institucional han de exigir al Estado, su obligación de garantizar a todos los miembros de la familia y de las familias el goce de los derechos: seguridad social, vivienda digna, educación, trabajo, recreación, libertad de conciencia, entre otros; que permitan a sus miembros y a la familia en su totalidad realizarse integralmente. Así mismo se debe promover la creación de políticas públicas que hagan viable el goce de dichos derechos, la promoción, ayuda y protección de la familia en todas sus etapas y situaciones particulares.

8. Finalmente la Iglesia en su acción pastoral no puede partir del rechazo y de la negación de las nuevas formas de familia, tanto en la evangelización como en la promoción humana que realiza a nivel local, nacional y mundial. Puesto que son una realidad socio-cultural y jurídica; su 
negación impide la acogida y el diálogo crítico y constructivo. Es necesario pues, tener en cuenta que si se rechazan estas nuevas formas de familia, no se tiene cómo promover que se forme a los hijos y a los demás miembros en valores cristianos, ni mucho menos que se integren a la vida eclesial. Lo que ocasionará la descristianización de un sector grande de la población y el "indiferentismo" social frente a la fe, a la doctrina y vida cristiana, y la Iglesia como comunidad de comunidades y como institución.

En este sentido cabe recordar las palabras del Papa Francisco: "la Iglesia no es una aduana, sino una casa de puertas abiertas". Por lo que las actitudes de acogida, acompañamiento y discernimiento pastoral propuestos en Amoris Laetitia, capítulo octavo, serán fundamentales en este nuevo proceso de diálogo constructivo y encuentro: entre la Iglesia y la Familia.

\section{Conclusiones}

1. El Estado colombiano en la Constitución Política de 1991 y en su desarrollo constitucional posterior, reconoce a la familia como "sujeto de derecho" y le asigna responsabilidades, para realizar su misión como célula fundamental de la sociedad, vivir en armonía y promover el bienestar y la felicidad de sus miembros. (Ministerio de la Protección Social, 2012).

2. El reconocer que la familia en su identidad y en su expresión es de naturaleza cultural, conlleva a aceptar la evolución del concepto, de las nuevas formas de familia y de las relaciones de familia ad intra y ad extra de las mismas. Dicha realidad permite exigir del Estado la implementación de políticas públicas para hacer viables y garantizar los derechos de todos los integrantes de la familia y de ella como tal, principalmente de los más vulnerables.

3. Los cambios sociales, jurídicos y culturales que ha experimentado la familia en Colombia, con todas las dificultades que a nivel interno le han generado, también le han permitido convertirse en sus nuevas formas y expresiones en agente político promotor de los derechos colectivos de la familia y a la vez responsable de los derechos individuales de cada uno de sus miembros.

4. Es mediante un diálogo constructivo y crítico con la familia, con las nuevas formas de familia, con las personas concretas, con el Estado y 
todas las fuerzas vivas de la sociedad que se puede iluminar estas nuevas realidades con la luz del evangelio y la doctrina de la Iglesia sobre el matrimonio y la familia, para llevarlas a un encuentro vivo con Jesucristo que ama, sana, libera y restaura.

5. El gran aporte de Amoris Laetitia consiste en que es un documento fruto de un análisis muy realista de la situación actual del matrimonio y de la familia en sus aspectos afectivos, sociales, culturales, jurídicos y aterriza en los problemas concretos de la vida familiar moderna como falta de trabajo, violencia, drogas, la migración, etc. Sin desconocer aspectos positivos de la familia como la paciencia, la generosidad, la esperanza, la solidaridad, el perdón y la fuerza espiritual ante la adversidad y la soledad, entre otras. Al tiempo que abre nuevos caminos a la pastoral, e invita a redescubrir la belleza del matrimonio y de la vida familiar como aporte a la construcción de la sociedad.

6. Tanto la relación final del Sínodo de la Familia como el Papa Francisco en Amoris Laetitia, convocan a la Iglesia en el desarrollo de su labor humanizadora y evangelizadora, a la promoción integral de las personas, de la familia y de las familias actuales, con sus grandes valores y también con sus dificultades, lo que permite su participación gradual y procesual en la vida y misión del cuerpo místico de Cristo. Esto le permite a la Iglesia proyectarse y ser realmente instrumento del Reino de Dios y Sacramento Universal de Salvación.

\section{Referencias}

Ares Muzio, P. (2009). Psicología de la Familia; facultad de Ciencias Psicológicas. Guayaquil: Universidad de Guayaquil.

Cabanellas de Torres, G. (2009). Diccionario Jurídico Elemental. Buenos Aires: Editorial Heliasta.

Colombia, Corte Constitucional (1995, 17 de enero), T-012, MP: Vladimiro Naranjo Mesa. ref.: Expediente No. T-44.888.

Colombia, Corte Constitucional (1993, 15 de mayo), T-190, MP: Eduardo Cifuentes Muñoz. ref.: Expediente T-8658.

Colombia, Corte Constitucional (2009, 26 de agosto), T-572, MP: Humberto Antonio Sierra Porto. ref.: Expediente T- 2.247.179.

Colombia, Corte Constitucional (2004, 25 de abril), T-292, MP: Manuel José Cepeda Espinoza. ref.: Expediente T-757783. 
Colombia, Corte Constitucional (2011, 26 de julio), C-577, MP: Gabriel Eduardo Mendoza Martelo. ref.: Expedientes acumulados D-8367 y D-8376.

Concilio Ecuménico Vaticano II (2004) Vaticano II. Madrid: Biblioteca de Autores Cristianos.

Constitución política de Colombia 1991 (2011). Bogotá: Colección: Constitución. Banco de la República.

Departamento Administrativo Nacional de Estadisticas DANE (2010). Encuesta Nacional de Demografía y Salud -ENDS 2005- 2010.- Bogotá.

De León Willis, J. (2012) Nuevas formas de familias. El caso de parejas del mismo sexo en la ciudad de Bogotá [Tesis de maestría]. Bogotá: Universidad Nacional de Colombia, Facultad de Ciencias Humanas, Departamento de Trabajo Social.

Petit, E. (1976) Tratado elemental de derecho romano. Fernández Gonzales (Trad.). México: Editora Nacional.

Papa Francisco (2016). Exhortación Apostólica Postsinodal "AMORIS LÆTITIA". Ciudad del Vaticano: Ediciones Vaticanas.

Juan Pablo II, (1981). Exhortación Apostólica "Familiaris Consortio". Ciudad del Vaticano: Ediciones Vaticanas.

Ferrari, V. (2012). Derecho y Sociedad elementos de sociología del derecho. Bogotá: Universidad Externado de Colombia.

Fichter, J. (1975). Sociología. Barcelona: Herder.

Concilio Vaticano II. (2004). Gaudium et Spes, la Iglesia en el mundo contemporáneo. Madrid: Bibliteca de Autores Cristianos.

Gutiérrez de Pineda, V. y Vila de Pineda, P. (1988). Honor, Familia y Sociedad [1a edición, p. 29]. Bogotá: Centro Editorial Universidad Nacional de Colombia.

Relación final del sínodo de los obispos al Santo Padre Francisco (2015, 15 de octubre). La vocación y la misión de la familia en la iglesia y en el mundo contemporáneo. Ciudad del Vaticano.

Parra Bolívar, H. (2005) Relaciones que dan origen a la familia. [Tesis de pregrado]. Universidad de Antioquia. Facultad de Derecho y Ciencias Políticas. Medellín: Universidad de Antioquia.

Rico de Alonso, A. (1999). Formas, cambios y tendencias en la organización familiar en Colombia. Nómadas (Col), núm. 11, octubre, 1999, pp. 110-117. Bogotá: Universidad Central.

Monroy Cabra, M. (2007). Ensayos de teoría constitucional y derecho internacional. Bogotá: Editorial Universidad del Rosario.

Papa Juan pablo II (1993). Carta Encíclica "Veritatis Splendor". Ciudad del Vaticano: Ediciones Vaticanas. 